\title{
Research on Teaching Model of Project-driven HCl Course
}

\author{
Xu Hongyan ${ }^{\mathrm{a}, \mathrm{b}}$, Wu Zhiming ${ }^{\mathrm{a}}$, Lin Tao ${ }^{\mathrm{a},{ }^{*}}$, Tang Ningjiu ${ }^{\mathrm{a}}$, Chen $\mathrm{Yu}^{\mathrm{a}}$
}

a. College of Computer science,Sichuan University ,Chengdu Sichuan 610065;

b. TianFu College,Southwestern University of Finance and Economics, Mianyang Sichuan 621000

Keywords: $\mathrm{HCl}$; Project-driven ; Teaching model

Abstract. Human-Computer Interaction(HCI) is a compulsory course in software engineering. This paper proposes a project-driven mode for HCI courses on the basis of analyzing the courses' characteristics and existent problems. Then, the outline, teaching method, process of HCI courses are made and introduced based on the proposed project-driven mode. This mode has achieved the goal of human-computer interaction course and worked well in the process of teaching.

\section{INTRODUCTION}

${ }^{1}$ With the development of the information technology, there is a fierce competition in the software market, and the usability of these software products becomes the key of gaining success. Thus, interaction designers, visual designers and software engineers are necessary for the development of software products. Among them, interaction designers are responsible for designing the interaction model, style and experience of the function of the products while the visual designers are for beautifying the pages and the program designers are for realizing the function of the products. However, program designers often do the work of the interaction design due to the limited development cost and human resource. Therefore, in order to produce high-usable and wellexperienced products, it is meaning for the programmers to study the knowledge of interaction designing and have a master of its methods.

The technology of HCI contributes to the development of software engineering technology, which hasn't definitely stated how to gain and analyze the user's page and usability. And the test of its usability hasn't emphasized in the developing process of its system, which results in the low-level usability and satisfaction of some products, though these products can be used. In the process of developing software, about $80 \%$ maintenance cost is related to system interaction, of which $64 \%$ is due to usability problems. However, the introduction of the interaction design and technology can solve these problems effectively [1]. The interaction course of people and computers has already stipulated as one of the compulsory courses in the international teaching standard SWEBOK of the software engineering major, which embodies the importance of this course. Bibliography [2] has also listed this technology as one of 25 compulsory skills that need to be mastered by the software engineers. Universities at home has also paid enough attention to the importance of this interaction technology in the process of the software engineering teaching. And more and more software colleges are trying positively to join them together.

HCI course is aiming to impart the basic knowledge of HCI systematically, principle and basic method of interaction system designing. Through the study of this course, students will form the developing idea of User-Centered Design (UCD), and have a master of the basic principle, method, related technique and the general process of the interaction system design. Thus, the ability and the quality of software design and development have been cultivated.

\section{TEACHING CHARACTERISTICS AND PROBLEMS OF THE INTERACTION COURSE}

a. The authors are with the College of Computer Science, Sichuan University, China. No.24 South Section 1, Yihuan Road, Chengdu , China, 610065

b. The author is with TianFu College, SouthWestern University of Finance and Economics, Mianyang Sichuan 621000

* corresponding author: Tao Lin is with the College of Computer Science , Sichuan University, China. No.24 South Section 1,

Yihuan Road, Chengdu, China, 610065

Email: lintao@scu.edu.cn 
HCI is a new inter-discipline which is about the design, realization, evaluation and the related phenomenon of the interacted computer system [3]. However, with a short history, this course is very difficult to teach. And the existent problems are as the following:

(1) How to decide the relationship between the HCI course and the Software Engineering course. In the researching field, they are regarded as the independent disciplines. Interaction designers start from the points of the users, which focuses on the usability, experiencing demand and the related techniques, while the software engineers begin from the visual angle, which focuses on the function realization [4]. At present, the prior difficulty is to work out the teaching methods and outline of the software engineering teaching on the basis of the clear status of this new course in the software engineering courses combined with the traditional software teaching.

(2) This course has a high requirement of the teachers and students owing to its theoretical, comprehensive and practical characteristics. Because it is a new discipline which has a lot of abstract theories and also involved with psychology, design, sociology and HCI engineering. It not only emphasizes the theoretical knowledge and the method of solving the problems, but also the engineering practice of the interaction design. Hence, in order to teach students who major in software engineering, teachers need to have a knowledge of the software engineering method and techniques and the interaction designing experience.

(3) Compared with the traditional software engineering knowledge such as data structure, algorithm and programming language, the teaching and promoting of this course still has a long way to go. Nowadays, the consciousness of UCD design is weak in the software development enterprises. Therefore, there is a relatively huge gap between the knowledge gained through campus education and the important level of this course [1].

(4) It's easy to know, but it is difficult to practice, resulting in the separation of the theory and practice. Because it is a new course with a few teaching materials that focuses on the theoretical knowledge, it tends to cause the separation of the theory and practice. However, this course has a very high requirement of practice. Although some course designs meet the demands of experimental teaching, they generally dwell on one method of organizing students to complete the interaction design. Owing to the lack of realistic practice, the teaching result is not satisfying.

(5) Problem solving uncertainties. During the design process interactive system, for some solution to the problem is not unique, but many or many-solving ideas, with great uncertainty. This differs from other software professional courses (programming), likely to cause students to feel abstract when learning abstract content, and difficult to correctly applied flexibly.

Combining features of interactive course, this essay proposed a complex project-driven teaching mode. It is the main project, the students participate in the analysis, design and evaluation of an interactive system in the form of the project team, the project implementation process, to guide students to independent thinking and innovation, will explain the application of knowledge into the curriculum of each individual project links, so that students application ability, ability to cooperate and UCD design and other professional quality has been effectively improved..

\section{ProjeCT-DRIVEN TEACHING MODEL}

\section{A. Project practice-centered curriculum}

For a limited number of hours of teaching both normal teaching to complete the interactive content, but also the systematic implementation of the project practice task, we developed a project centered on the practice course syllabus, the basic idea is to practice throughout the project interactive teaching process, teaching basic content around the project practice. First, the outline of the teaching process is divided into seven basic parts: (1) the basics of HCI; (2) the objectives and principles of interaction design; (3) the availability and assessment methods; (4) user-centered interaction design process; (5) interactive system requirements capture and analysis; (6) interactive system design; (7) interactive system evaluation. The first four mainly composed of teachers teach the basics of HCI and interaction design process framework, so that students have a general 
understanding of the interactive system design. After the completion of the first four parts, the project topic guide, practice students into the project stage. That is, at the same time teaching part of the teaching content of 5-7, project practices. For example, the completion of the teaching content Part 5 at the same time needs analysis practical guidance, including people-oriented requirements capture and modeling, completing Section 6 teaching interactive system conceptual design and physical design practice guidance at the same time, the last in Part 7 while interacting systems evaluate teaching practices. The total number of class hours of 80 hours, 48 hours of theory lectures, experimental guidance 32 hours, so interactive course syllabus project centered practice effectively ensure the systematic and complete project practice.

\section{B. Practice teaching method of project-driven}

Practice Teaching interactive project consists of three parts: theoretical lectures, staging practice reports and seminars.

(1)Theory taught. HCI to explain the basic concepts, principles and methods. For important and difficult knowledge, mainly through situational teaching, with examples, change the abstract concrete, solve difficult clarifying teachers and students to understand difficult issues, so as to effectively achieve succinctly and focus.

(2)Sub-practice report. Project practice report of the project at different stages. Different stages have different reporting requirements. Demand interactive system build, for example, students as a group, need to submit a report on the needs of users of the project needs to be carefully describe the target users and their perception and cognitive characteristics, access method needs, requirements analysis methods and demand analysis.

(3)Symposiums. The purpose of the symposium is to discuss some general or against controversial issues during the project exists. The topics can introduce ourselves by the student or assigned by classroom teachers. The spokesman explained in detail the problem, focuses on the perspective of the problem, and then supplemented by other students, for a full discussion of controversial views, and finally summarized by the classroom teachers. Teachers should not only evaluate whether the summary obtained the correct result, but should emphasize the correct results of the process and methods, or encourage students to make better programs.

\section{Implementation Practical Project}

Project practice is guided by the interactive design process model Preece proposed $[5,6]$, the model consists of four phases:

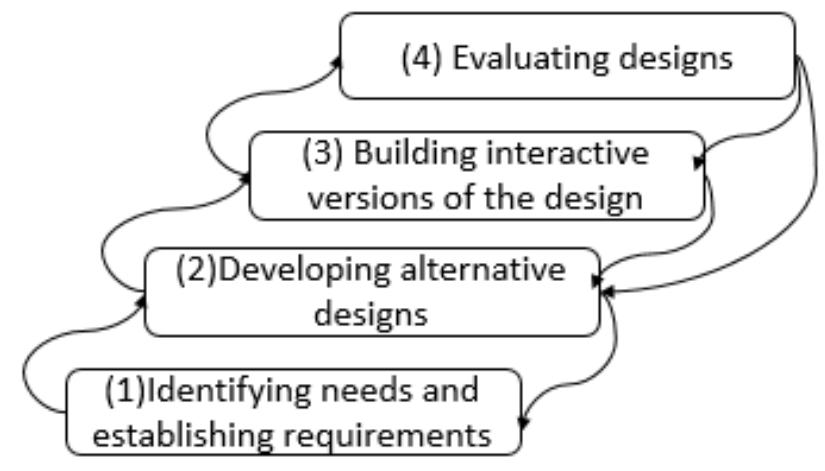

Figure 1 Four-stage model of interaction design proposed by Preece

(1)Identify needs and establish requirements. The first stage to guide students on how to select the target user, follow the " $5 \mathrm{~W}+\mathrm{H}$ " information gathering principle, the use UCD method (observation, interviews, questionnaires, focus groups, etc.) to get the user needs. Then guide students to use task analysis, for example, storyboards and other tools used to analyze and build requirements. Demand mainly includes four aspects: functional requirements, data requirements, environmental requirements, availability and user experience requirements. Among them, the target user's 
perception, cognition and interactive environment and other characteristics, availability and experience requirements established method utilizing UCD is the focus of this stage.

(2)The development of alternative multiple design alternatives. Design is divided into Conceptual Design (Conceptual Design) and physical design (Physical Design). Conceptual design method mainly include brainstorming, card sorting, semantic networks, roles, plot, flowcharts, and cognitive walkthroughs and so on. Physical design mainly using rapid prototyping methods (horizontal and vertical prototype prototype), requires students to design a physical interface, the follow interaction design principles proposed by Shneiderman [7].

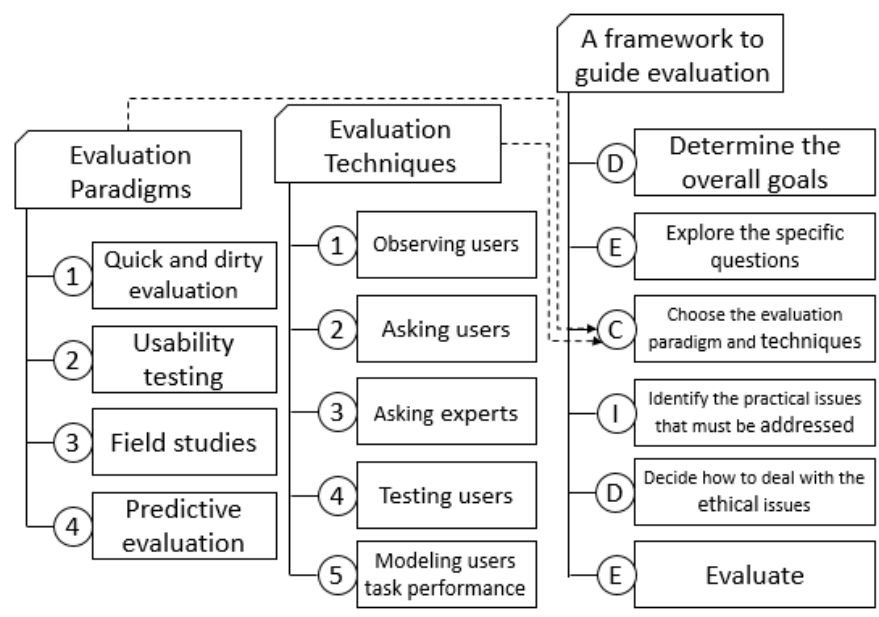

Figure 2 Evaluation System proposed by Preece

(3)Construction of interactive prototyping solutions. Interactive prototype is the designer and user communication link. This stage refers to the relatively "stable" on the basis of the design of further build interactive prototypes to be used for user evaluation found design problems. This course emphasizes the student's "Design" capabilities, rather than software development capabilities. Therefore, at this stage to encourage students to use rapid prototyping tools (such as Axure) to create interactive prototypes.

(4)Evaluation design. Use different forms of assessment at all stages of the process will be interactive. There is no general assessment of interaction design patterns and methods, generally you need to choose according to specific requirements. This course emphasizes usability and user experience assessment, reference Preece proposed "DECEDE" evaluation system to guide the assessment process (Figure 2), namely four kinds of paradigm, 5 class technology and six steps.

In the interactive design process (Figure 1) has three key features: "user-centric", "OK availability and user experience goals," and "iteration." (4) the first step is to use the prototype step (2) to evaluate programs, identify problems, the results back to the first step (2) amend the design, and then repeat step (3) and (4) until the assessment to meet the requirements. Therefore, from the first step (2) to (4) is an iterative process.

\section{Practice requirements}

Project of the project is to ensure that the requirements for effective teaching practice, the specific requirements are as follows:

(1)The project team to 4-6 is appropriate, each group a leader, responsible for organizing and coordinating the entire project team leader has the responsibility to work on a regular basis to reflect the status of the instructor team members.

(2)Project Selection completed by students and teachers. Subject to student interest led, teachers need a good grasp of the depth and breadth of the subject. The selected topic should be of a certain size actual interactive systems, knowledge in the field of the systems involved should have some understanding of the student or the student easy to understand, and that the chosen system should 
focus on the lives of students, help students UCD methods use practices. Such as curriculum-based mobile platform systems, school systems and other electronic sales.

(3)Through the project practice UCD master the basic principles of interaction design, methods and steps, learn to use rapid prototyping tools (such as Axure) quickly build interactive systems, and evaluate practice. People-oriented needs analysis is the key project of practice, students also need to exercise the most part. Before the project needs analysis, teachers and students to discuss specific issues that need investigation, to enable students with problems to research. For example, consciously allow students to use UCD methods for the collection and create a user usability and user experience requirements.

(4)At various stages of the project carried out by the teachers' organizations to discuss project review will require each group to report project progress and achievements of teachers and students to answer questions, and submit the form team of the week working with reports, documentation, system prototypes material.

(5)Curriculum assessment is divided into theoretical and practical assessment examination of two parts. Theoretical examination take open-book examination, focusing on assessing students' mastery of basic concepts and principles; students practical examination results by the team scores and individual scores of two parts, according to the project team score knot material submitted by each group, and combined with project situation report assessment; individual results according to the weekly report on the work and task tracking table a comprehensive evaluation by the team leader and teacher.

\section{CONCLUSION}

Project practice-centered interactive teaching model to improve students' ability to apply knowledge of interaction design goal, the effective implementation of the interactive course teaching purpose, it is software engineering professional interactive teaching has made a new meaning attempt. Students generally reflect innovative teaching methods, teaching content practical, is a useful complement to other professional courses, especially for students with user-centric consciousness has laid a good foundation. However, there are still some problems to be solved implementation of this teaching model. HCI is a typical interdisciplinary field, involving a wide range of knowledge, and student knowledge single large extent affected the effectiveness of teaching interactive courses. By means of project-centered practice interactive teaching mode, we can develop students' independent initiative to acquire, use, ability to find knowledge, so that they become adapted to the requirements of the new era of software development personnel. This teaching method will inevitably be subject to some restrictions objective or subjective factors also need to be further improvement in the constant teaching practice.

\section{ACKNOWLEDGMENTS}

This study was partly supported by the Science and Technology Supporting Program, Sichuan Province, China (No. 2013GZX0138, No.2014GZ0154) and the Scientific Research project, Education Department of Sichuan Province, China (15ZA0324)

\section{REFERENCES}

[1] M. LUO Bin,FENG Gui-huan. Human-Computer Interaction : A Software Engineering Perspective. China Machine Press. 2012.:45-60.

[2] J. Lethbridge, T.C.. "What knowledge is important to a software professional? " Computer, 2000. 33(5): 44-50.

[3] M. Hewett, T., et al.. ACM SIGCHI Curricula for Human Computer Interaction. Chapter 2: Human Computer Interaction[M], ACM.2003: 5-27.

[4] M. PENG Jia-hong,CAO Xiao-lan,CHENG Yan. "Research of Software Engineering System and Curriculum. ” Higher Agricultural Education, 2013(02): 74-76.

[5] M. Preece, J., Y. Rogers, and H. Sharp. "Interaction design : beyond human-computer interaction. ” New York, NY: Wiley \& Sons. 2002: 317-355

[6] M. LI Shi-Guo,GU Zhen-yu. Interaction Design. China Water\&Power Press. 2012:163-170 
[7] M. Heim, S.G.. The Resonant Interface: HCI foundations for interaction design. Pearson/Publishing House of Electronics Industry. 2007:193-228 